\title{
Access to Meckel's cave for biopsies of indeterminate lesions: a systematic review
}

\author{
E Suero Molina ${ }^{1}(\mathbb{D}) \cdot \mathrm{JM}$ Revuelta Barbero ${ }^{2,3} \cdot$ C Ewelt $^{1} \cdot$ W Stummer $^{1} \cdot$ RL Carrau $^{2,3} \cdot$ DM Prevedello $^{2,3}$
}

Received: 18 October 2019 / Accepted: 20 January 2020 / Published online: 10 February 2020

(C) The Author(s) 2020

\begin{abstract}
Accessing Meckel's cave (MC) is surgically challenging. Open approaches are complex and often correlated with high morbidity. Endoscopic approaches emerged in the last decade as feasible alternatives to open approaches, especially for sampling indeterminate lesions. This article first analyses available routes to approach Meckel's cave and presents furthermore an illustrative case. We conducted a systematic review and reported according to the guidelines for preferred reporting items for systematic reviews and meta-analyses (PRISMA). Various surgical approaches identified through the search are evaluated and discussed in detail. Additionally, we report on a case of woman with a lesion in MC, which was accessed through an endoscopic transpterygoid approach subsequently diagnosed as a diffuse large B cell lymphoma. Our search delivered 75 articles that included case reports $(n=21)$, cadaveric studies $(n=32)$, clinical articles $(n=16)$, review of the literatures $(n=3)$, as well as technical notes $(n=2)$ and a radiological manuscript $(n=1)$. Open routes included lateral approaches with many variations, mainly intra- and extradural pterional approaches and anterior petrosal, as well as a retrosigmoid intradural suprameatal and a lateral transorbital approach. Endoscopically, MC was reached via approaches that included transpterygoid, transorbital or infraorbital fissure routes. Percutaneous approaches, e.g. through the foramen ovale, were also described. Multiple surgical approaches to MC are currently available. Their different characteristics as well as individual patient factors, such as clinical history and the localization of the disease, have to be considered when choosing a surgical corridor. Studies included in this review highlight the endonasal endoscopic transpterygoidal technique as an excellent corridor for biopsies in the ventral MC.
\end{abstract}

Keywords Meckel's cave · Approaches $\cdot$ Indeterminate lesions $\cdot$ Endoscopic endonasal approach $\cdot$ Skull base surgery

\section{Introduction}

Named after Johann Friedrich Meckel, a German anatomist, the cavum meckeli, also known as Meckel's cave, trigeminal cave or cisterna trigeminalis, is a region with a complex

Electronic supplementary material The online version of this article (https://doi.org/10.1007/s10143-020-01247-w) contains supplementary material, which is available to authorized users.

E Suero Molina

eric.suero@ukmuenster.de

1 Department of Neurosurgery, University Hospital Münster, Albert-Schweitzer-Campus 1, A1, 48149 Munster, Germany

2 Department of Otolaryngology-Head and Surgery, The Ohio State University, Wexner Medical Center, Columbus, OH, USA

3 Department of Neurological Surgery, The Ohio State University, Wexner Medical Center, Columbus, OH, USA neurovascular array and, therefore, anatomically speaking, presenting a surgical challenge.

Meckel's cave is located at the petrous apex between two dural layers originating from the floor of the middle fossa and dividing at the trigeminal notch, complemented by the dura propria of the posterior fossa [1-3]. Laterally, Meckel's cave is limited by a meningeal layer covering the temporal lobe, whereas its medial wall separates the intercavernous carotid and sphenoid body from the trigeminal nerve [3]. Infero-medially, Meckel's cave meets the bony part of the temporal fossa, as well as the petrous carotid canal $[4,5]$.

Due to Meckel's cave location interfacing the posterior and middle fossae, lesions can spread between compartments, and thereby requiring access through a multi-corridor surgery.

External approaches have been historically applied to access this region [6-9]. The introduction of rod-lensendoscopes allowed for minimal-access routes to the sellar and parasellar region affording exposure of the anterolateral and inferior portion of Meckel's cave [5], thus improving 
cosmetic results and potentially decreasing surgical morbidity [10]. Since these approaches offer a wide visualization of relevant structures through a small surgical window, both biopsies and larger resections are feasible [5, 7, 11-14].

In lesions where the junction of clinical, radiological and laboratory data are not conclusive to suggest a therapy algorithm, tissue sampling might be imperative to establish a definitive diagnosis and treatment plan. This study aims to analyze different surgical approaches to reach Meckel's cave for tissue sampling of such indeterminate lesions.

\section{Methods}

\section{PRISMA literature search protocol}

In this article, we searched and reported according to guidelines established by Preferred Reporting Items for Systematic Reviews and Meta-Analysis (PRISMA statement). The protocol included articles published until November 2018 without omission of earlier dates. Terms for searching title and abstract were "Meckel's cave" and "biopsies", "Meckel's cave" and "biopsy", "Meckel's cave" and "endoscopic", "Meckel's cave" and "approach", "Meckel's cave" and "door", "Meckel's cave" and "access", and "Meckel's" and "resection". Articles delivered by the initial search were screened for duplicates and non-English abstracts. After eliminating these studies, abstracts were screened and relevant full-texts were evaluated. The search was conducted according to the outlined protocol using commercially available software (Endnote X7, Thompson Reuters, Carlsbad, California, USA).

\section{Results}

The initial search yielded 271 articles. First, duplicates $(n=$ $89)$ and non-English abstracts $(n=25)$ were removed; thereafter, 157 abstracts were screened for relevance resulting in the full-text evaluation of 112 articles. Subsequently, 75 articles were identified for our qualitative synthesis and included case reports $(n=21)$ [15-35], cadaveric studies $(n=32)$ [3, 6, $7,10,13,36-60]$, clinical articles $(n=16)[2,5,8,9,16$, 61-71], review of the literatures $(n=3)$ [72-74], as well as technical notes $(n=2)[75,76]$ and a radiological manuscript $(n=1)$ [77]. These outlined articles were published between February 1978 and November 2018. Additional citations were included when relevant. Rather than describing each approach in detail, the study aimed to outline essential information. The authors refer to the respective publications for further details.
Approaches to Meckel's cave in the literature (Fig. 1)

\section{Antero-medial}

Extended endonasal endoscopic-assisted approach (with illustrative case) Endoscopic approaches to the skull base are promising due to improved visualization and reduced morbidity in comparison to external approaches. Furthermore, they lack the need for crossing cranial nerves and vessels [7]. In a sufficiently pneumatized sinus, a wide sphenotomy will already provide access to the anterior portion of Meckel's cave $[12,58,74]$. However, this might not be sufficient if targeting the lower lateral skull base [53]. For more extended visualization of Meckel's cave, several approaches have been reported in the literature:

\section{Transpterygoid approach}

The transpterygoid approach extends the endonasal corridor to address tumors in the middle and posterior fossa [77]. Removing the medial aspect of the pterygoid process base can already provide sufficient access to Meckel's cave [17]. An ipsilateral middle turbinectomy and uncinectomy, followed by a posterior ethmoidectomy and a wide sphenotomy are normally performed [5]. Lateralization of the inferior turbinate and the contralateral middle turbinate by out-fracturing their bony attachment can increase working space [78]. Additionally, a wide maxillary antrostomy with lateral exposure of the infraorbital fissure with its neurovascular structures can increase the panoramic view of the skull base $[5,70]$. The

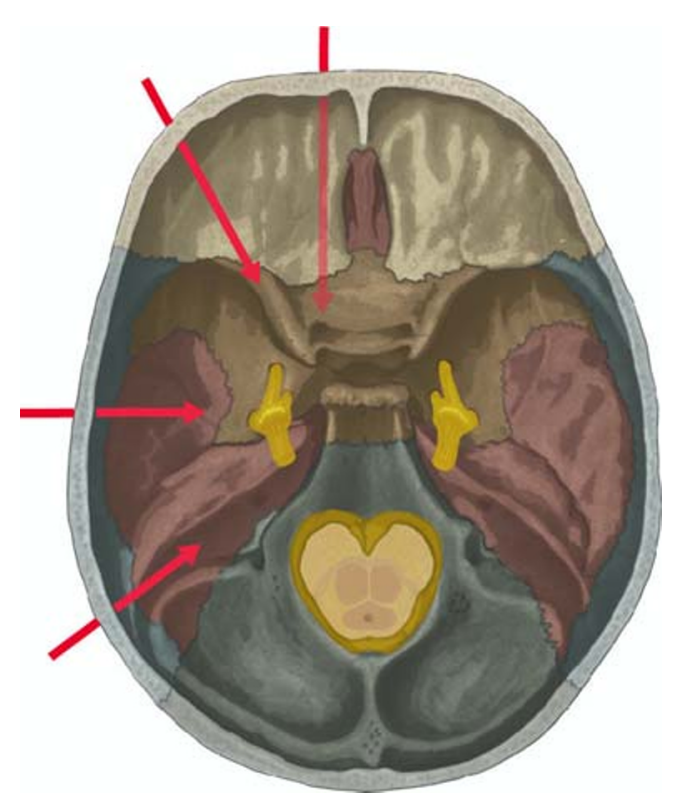

Fig. 1 Skull base illustration highlighting available routes to Meckel's cave. These can be divided in antero-medial, antero-lateral, lateral and posterior (red arrows from upper right to lower left, respectively) 
infraorbital nerve delineates the pterygopalatine fossa (PPF) laterally increasing orientation during the procedure.

The Vidian nerve and artery have become an important landmark to identify the inner anterior genu of the petrous segment of the ICA, for improving depth perception during the surgical procedure and avoid injury of the ICA $[7,11,38$, 77-79]. The Vidian neurovascular bundle is identified where the medial pterygoid plate meets the floor of the sphenoid sinus, in average $12.78 \mathrm{~mm}$ (range $9.4-15.8 \mathrm{~mm}$ ) from the midline [77]. This bundle can be either coagulated and divided $[5,78]$, facilitating lateralization of the PPF content, i.e. int. max. art, V2 and pterygopalatine ganglion [7], or preserved if approaching strictly superior to the Vidian nerve $[14,70]$. The Vidian nerve, however, transports sympathetic and parasympathetic fibers important for lacrimation [7]. Hence, Vidian nerve injury can impair lacrimation in the ipsilateral eye. The complex relationship of the ICA at the posterior limit of this route with the Vidian nerve and the quadrangular space is essential for the safety of these surgeries $[44,52,80]$. Skeletonizing the ICA is only required if mobilization is needed for posterior access [7].

A quadrangular space delineated by the ICA medially and inferiorly, the V2 nerve laterally, which is superolateral to the ICA [7], and the abducens nerve with the CS superiorly, provides access to Meckel's cave [79]. The ICA course should be carefully studied to define the feasibility of this approach [13] and avoid injury while drilling.

To prevent injury of the abducens nerve, V2 should not be crossed superiorly and intraoperative electrophysiological monitoring should be applied [5, 39]. Furthermore, drilling near the petrous apex can induce thermal injury of the $\mathrm{VI}^{\mathrm{th}}$ nerve [39]. As an orientation, the superior part of the lacerum segment of the ICA correlates with the dural entry point of the $\mathrm{VI}^{\text {th }}$ nerve posteriorly [39]. Access to the petrous apex requires bypassing the ICA [50]. This route carries limitations for lesions extending into the posterior fossa. However, lesions in the anterior-medial and inferior portion of Meckel's cave can be easily accessed.

\section{Illustrative case}

A 78-year-old female patient presented to the James Comprehensive Skull Base and Pituitary Center, Columbus, Ohio, USA due to a progressive cranial nerve VI palsy, retroorbital pain and proptosis on the right side. The patient had a pre-medical history of non-Hodgkin lymphoma with a newly identified Meckel's cave mass (Fig. 2).

Intending biopsy, the lesion in the right Meckel's cave was accessed through an extended endonasal endoscopic-assisted transpterygoidal approach (Video 1; Fig. 3). A free mucosal graft was employed for reconstruction of the skull base defect (from the right middle turbinate). The mass was later diagnosed as a diffuse large B cell lymphoma with double expressor (C-MYC+ and Bcl-2+). More in detail, the tumor was classified as germinal center type given CD10 positivity, in the presence of strong MUM-1 staining; these cases have been reported to follow a more aggressive clinical course. The patient postoperative recovery was uneventful. The right retro-orbital pain diminished and double vision improved. There was no sign of new facial numbness or paresthesia.

\section{Transmaxillary}

As an alternative to the transpterygoid approach, removing the posterior maxillary sinus will also lead to Meckel's cave [57, 60, 71]. Zhang et al. [60] described an endoscopic access through the inferior orbital fissure. They describe an approach lateral to the middle turbinate, where - after performing an uncinectomy and medial maxillectomy - the infraorbital neurovascular bundle could be transposed inferiorly, providing space for drilling the anterior portion of the sphenoid wing lateral to the foramen rotundum and gain anterolateral access to Meckel's cave. Previously, Bai et al. [38] described a similar approach reaching the anteromedial portion of Meckel's cave. As a variance, a sublabial transantral route might lessen the need of removing the anterior sphenoid wall $[10,57]$. An anterior antrostomy through a sublabial incision provides access superior to the alveolar ridge. Through the canine fossa, an anterior antrostomy is performed, and dorsal to the maxillary sinus, the infraorbital nerve and subsequently $\mathrm{V}_{2}$ are dissected to reach Meckel's cave. Access to Meckel's cave will, however, be limited [57]. These articles discuss the advantage of less manipulation to the structures within the pterygopalatine and infratemporal fossa, as well as within the cavernous sinus and the petroclival carotid, arguing to cause less trauma and providing a safer approach. However, the nasolacrimal duct needs to be transposed and the infraorbital neurovascular array with emerging nerves, i.e. the zygomatic or lacrimal nerve, manipulated; clinical sequela can therefore be of relevance.

\section{Transorbital}

Two cadaveric studies outlined the anatomical and technical nuances of the lateral endoscopic orbital route to access Meckel's cave [47, 54]. This corridor was used to reach the middle fossa and the lateral ventral skull base and Meckel's cave. The skin incision was made either in the superior eyelid [54], or at the inferior orbital rim [47]. Accessing through the lateral orbit and between the superior and inferior orbital fissure, a triangular [47] or trapezoid [54] shape craniotomy was described. Finding an extradural space superior to $V_{2}$ and by further drilling posterior to $V_{3}$, Meckel's cave could be accessed in an oblique anterosuperior way. The trigeminal nerve could be visualized from the cisternal portion in the posterior fossa until its division in $\mathrm{V}_{1}-\mathrm{V}_{3}$ [54]. Additionally, 


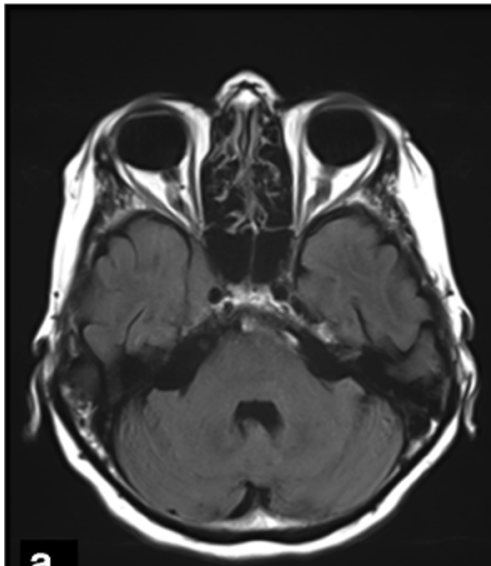

a

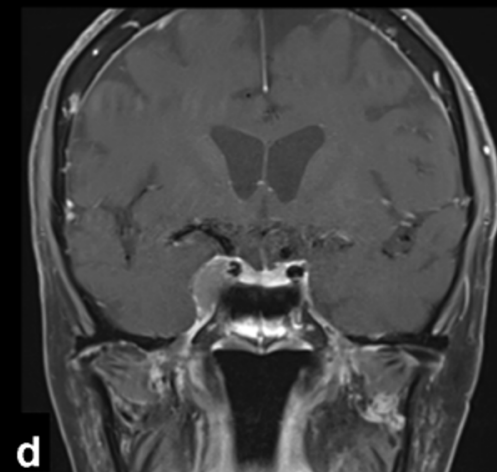

Fig. 2 Preoperative imaging of a 78-year-old female patient harboring a lesion in Meckel's cave. No hyperintensity was observed in the a FLAIRor b T2-weighted scan. There was however contrast-enhancement

the superior and posterior CS, as well as the superior petrosal sinus, were identified [47]. The region medial to V1 and posterior to the ICA appears an anatomical limitation of this
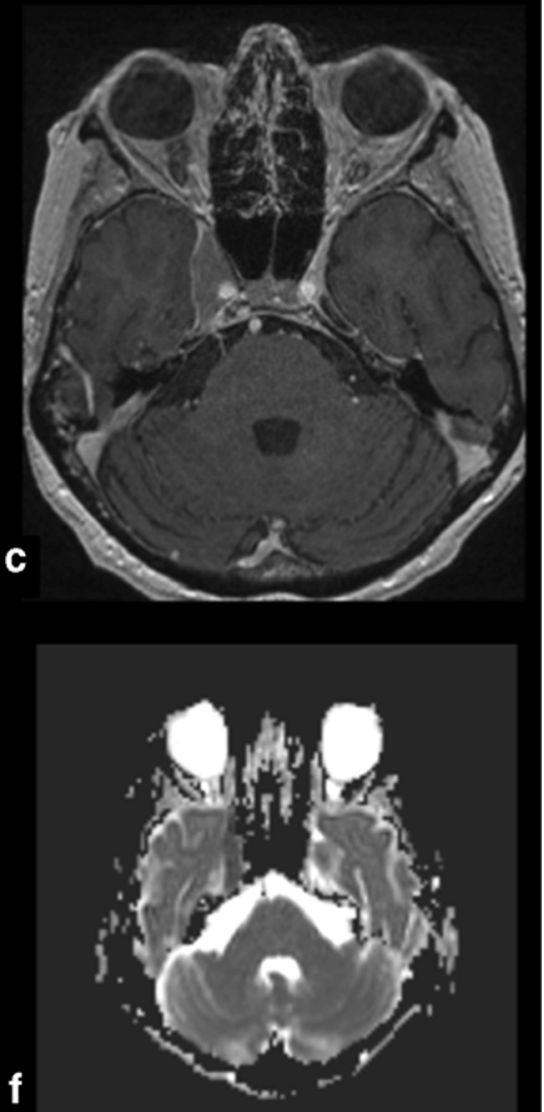

demonstrated in the $\mathbf{c}$ axial and $\mathbf{d}$ coronal T1-weighted imaging. No diffusion restriction could be seen in the e DWI, but hypercellularity was demonstrated in the $\mathbf{f} \mathrm{ADC}$-sequence

approach. This approach targets the anterolateral and superior region of Meckel's cave. Jeon et al. demonstrated in a recent series of nine patients, seven of them with diseases involving

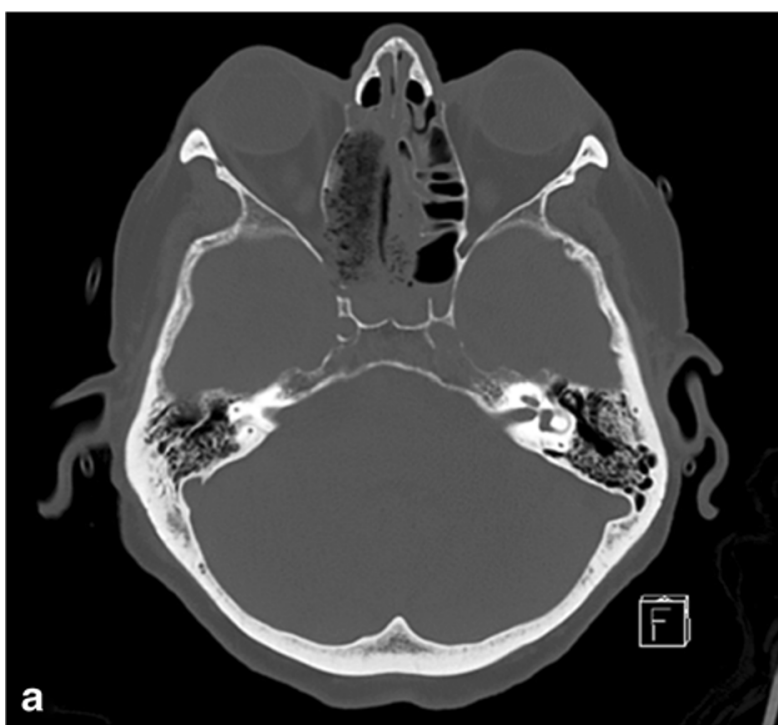

Fig. 3 Postoperative CT-imaging after endonasal endoscopic transpterygoidal approach to Meckel's cave with a bony and b tissue windowing demonstrating the bone access to Meckel's cave, as well as

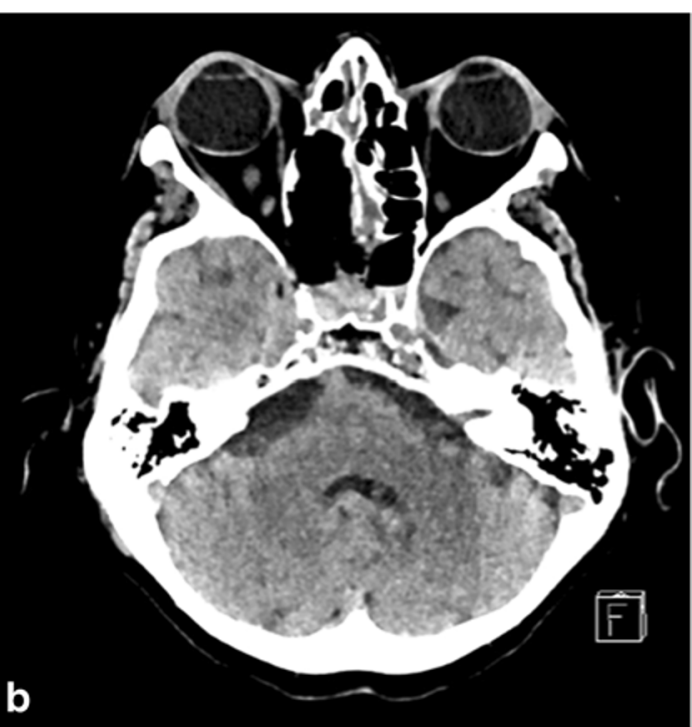

the defect after extended endonasal transpterygoidal approach with right side turbinectomy, uncinectomy, posterior ethmoidectomy and wide sphenotomy 
Meckel's cave, the feasibility of this novel technique [65]. Even though the sample size is small and the follow-up time was short, the authors reported low morbidity with a single patient suffering of ptosis, which eventually recovered after 6 months. Gross total resection was achieved in seven of nine patients.

\section{Percutaneous}

Transforamen ovale image-guided approaches are regularly used for rhizotomy in the context of atypical trigeminus neuralgia [81]. In 1997, Sindou et al. described the percutaneous approach to Meckel's cave for biopsies of indeterminate lesions, based on their trigeminal thermocoagulation experience [82]. CT-guidance might increase safety [35]. Even though this approach appears feasible, highly vascularized tumors can be of high risk for hemorrhagic complications. Tumor consistency is further important, since hard tumor tissue is difficult to aspirate through a needle [18]. Messerer et al. reported contamination of sample tissue with fat, CSF or blood, leading to diagnostic difficulties [83]. Drainage of arachnoid cysts, however, has been reported as feasible [21]. In the further course, an endoscopic transforamen ovale approach and observation of Meckel's cave were reported [48]. However, vision was restricted by the lack of space and mobility of the endoscope and by oozing from small veins. Variations of the internal maxillary artery can be of relevance and should be carefully evaluated preoperatively [37]. Nevertheless, this approach should be kept in mind as an option to manage indeterminate lesions, as it is associated with low morbidity and not all pathologies require a surgical therapy [18]. Hence, unnecessary open surgery could be avoided.

\section{Anterolateral and lateral approaches}

Anterolateral approaches consist of frontotemporal or orbitozygomatic approaches with intra- or extradural corridors. Major drawback from this corridor is the need of temporal lobe retraction, especially when targeting the inferior part of Meckel's cave. Augmenting this approach with an orbitozygomatic removal, as well as the dissection of the temporal muscle [31], can decrease retraction of the temporal lobe $[62,84]$. By opening the sylvian fissure, the view into Meckel's cave and cavernous sinus (CS) can be extended [4, $22,85]$.

When approaching from the extradural space, elevation of the middle fossa dura is limited medially due to attachment to the $\mathrm{V}_{3}$-Branch and the CS [6]. Furthermore, the meningeal medial artery at the foramen spinosum and $\mathrm{V}_{3}$ at the foramen ovale can be identified before exiting the skull base [6]. Skeletonizing the superior orbital fissure and foramen rotundum and ovale will help delineate the plane of dura elevation [56].
A frontotemporal extra-/interdural approach (Dolenc's approach [86]) can avoid exposition of the temporal lobe and enable exposure of the trigeminal ganglion [59, 62]. From lateral, Meckel's cave is best identified around $7.5 \mathrm{~mm}$ medial of the foramen spinosum and just posterior to the foramen ovale [6]. The meningeal dura is kept covering the temporal lobe and the entire lateral surface of Meckel's cave is exposed.

Most of these approaches were created to excise schwannomas or meningiomas in the petroclival or parasellar region $[67,68]$; they provide wide access to the superior lateral Meckel's cave in exchange of higher risk of morbidity.

\section{Subtemporal transpetrosal-transtentorial approach with anterior petrosectomy (Kawase-Shiobara approach)}

Kawase et al. described an anterior petrosectomy by removing the bone ventral to the IAM. This route can target pathologies in the upper petroclival region, Meckel's cave and brainstem $[1,55]$. There is a risk of $\mathrm{IV}^{\text {th }}$ nerve injury if the tentorium is incised with the aim to improve access to the infra- and supratentorial petroclival region [50]. However, this incision is not necessary in most cases.

Great superficial petrosal nerve (GSPN) is identified as an important landmark during anterior petrosectomy [66, 87]. Drilling anterior to the bone of the internal acoustic meatus can cause damage to the cochlea [6]. The approach will be limited by the lower edge of the porus trigeminus, inferior petrosal vein and the petrous ICA [6, 87]. Removal of the Kawase triangle is only essential when exposure of the ventral brainstem and clivus is needed $[1,88]$. Lesions from Meckel's cave with lateral or posterior fossa extension can be reached through this approach.

Excessive retraction of the temporal lobe should be avoided, since this could damage the V. Labbe [89], or induce seizures [90]. Further risks are cranial nerve or vascular injury, CSF leak and damage to the intrapetrous otologic structures, i.e. geniculate ganglion (facial palsy) or cochlea (hearing loss) [91]. To avoid brain stem and cerebellum edema, the superior petrosal vein should be sheltered [92].

\section{Postero-lateral}

\section{Retrosigmoid intradural suprameatal approach}

The retrosigmoid approach has been discussed as a route to the petroclival region since the beginning of the neurosurgical era [93]. As a modification of the retrosigmoidal approach for lesions extending to the middle fossa, postero-lateral approaches interconnect both the middle and the posterior cranial fossa $[8,72]$. Even though a semi-sitting position is commonly used, park-bench positioning might reduce the risk of venous air embolism. The surgical corridor consists of a retrosigmoid approach with additional drilling of the 
suprameatal bone prominence and the posterior portion of the petrous apex [51]. The latter step can further expose the lateral trigeminal nerve by an average of $10 \mathrm{~mm}$ (range $6-13 \mathrm{~mm}$ ) [3, $36,41]$. The trigeminal impression represents the anterior limit of the bony resection $[3,8]$.

Optionally, the tentorium can be divided above the $\mathrm{V}^{\text {th }}$ nerve for further access to the middle fossa. Drilling the suprameatal tubercle in a pyramidal shape, with the base towards the trigeminus nerve, can avoid injuries to both superior and posterior semicircular canal, as well as to the common crus of both canals [36]. Additionally, endoscopic-assistance with 0 - and 30-degree endoscopes has been reported to be feasible for identifying deep-seated neurovascular structures $[36,45,94]$. The trochlear nerve can be identified in the cisterna ambiens medially under the tentorium before trespassing dorsal to the posterior clinoid process [36]. The abducens nerve regularly lies underneath and medial to the IV ${ }^{\text {th }}$ cranial nerve traveling to the clivus before it enters into the Dorello's canal and towards the CS [36].

An advantage of this approach is that no blind tentorial splitting or petrosectomy is needed. However, risks that merit mention are cranial nerves and vessels injury, e.g. superior petrosal vein, sigmoid and transverse sinus, anterior and posterior inferior cerebellar artery, and potential injury through a cerebellum and brainstem retraction.

Other postero-lateral approaches with posterior transpetrosal modifications and presigmoid access can be retrolabyrinthine, translabyrinthine or transcochlear maximizing the petroclival window. Those bear, however, a greater risk of hearing impairment or facial palsy and normally do not provide enough exposure of Meckel's cave [95-97].

A partial labyrinthectomy petrous apicectomy combining potential advantages of retro- and translabyrinthine corridors has also been described as a modification of these approaches [40], but is likely to be too invasive if solely used for biopsies.

\section{Other approaches}

A midface degloving approach has been also described to access the anterior skull base [16]. However, approaching Meckel's cave required sacrifice of the maxillary nerve and the approach itself appears to be invasive in terms of scaring.

\section{Discussion}

Historically, approaches to Meckel's cave have been divided in anterolateral, lateral and posterolateral, comprising frontotemporal extra- or intradural, orbitozygomatic, subtemporal anterior petrosal, presigmoid posterior petrosal and suboccipital approaches [5, 43]. More recently, the anterior-medial route with the help of rod-lens endoscopy is providing minimal-invasive access to this region [70].
Expanse of Meckel's cave is predominantly determined by the size of the trigeminal ganglion. Its width correlates with the medial to lateral dimension, and its length with the distance from the trigeminal porus to the anterior edge of the trigeminal ganglion [6]. The dura carpeting the floor of the middle fossa, splits at the trigeminal notch in two-sheets that build the layers covering Meckel's cave and exit through the porus trigeminus posteriorly towards the posterior fossa [3]. The lateral dural wall is formed by the tentorium, whereas the cavernous sinus and the petrolingual ligament, as a continuity of the carotid canal periosteum, constitute the medial wall [2]. Meckel's cave interconnects the middle and posterior fossa and tumors can spread through these regions [98], creating unphysiological spaces, that should be considered for planning approaches. Content of Meckel's cave includes the Gasserian ganglion and postganglionic trigeminal rootlets lying in the trigeminal cistern [6]. In most cases, a thin bony lamina is found between trigeminal ganglion and internal carotid artery (ICA), but dehiscence occurred in up to $30 \%$ of analyzed specimens in a recent study [6]. The abducens nerve travels in the posterior inferior cavernous sinus, in close vicinity inferior and medial to the TG and Meckel's cave [43]. Oculomotor and trochlear nerve run superior to the trigeminal ganglion ( 5-6 $\mathrm{mm})$ [6].

\section{Differential diagnosis of lesions in Meckel's cave}

\section{Decision-making}

We have highlighted the anatomic limitations, technical nuances and potential advantages of each route. Especially for biopsies, a small window towards the lesion might be sufficient. A large portion of tumors in Meckel's cave will have an extra-/intradural location [67], intradural approaches are often not needed. However, case selection has been to date discussed according to the radiological appearance of lesions and their relationship to the dural sheets [2], which is not always feasible when dealing with the indeterminate lesions discussed in this article (Table 1). If a further resection is required, the feasibility of each approach need to be evaluated according to the specific anatomical situation.

Tumor consistency is important, as hard, fibrous tumors might require a wider exposure, than cystic or soft tumors, where a narrow approach could be sufficient [49]. Thorough imaging with MRI and CT is therefore essential. Cavernous sinus invasion is suspicious of meningioma or hemangiopericytoma [2]. Hence, an approach where further resection is possible should be chosen. Tumor extension might be the most important factor towards surgery planning of these lesions. Patient's morbidity and age might steer surgeons towards only biopsing lesions, or simply decompressing important neurovascular structures. Finally, the surgeon's experience will always lead the discussion. The available equipment 
Table 1 Differential diagnosis of lesions within Meckel's cave

\begin{tabular}{ll}
\hline Benign & Meningioma [61] \\
& Benign Schwannoma [61] \\
& Benign melanotic schwannoma [99] \\
& Xanthoma [100] \\
& Lipoma [61] \\
& Neuromuscular hamartoma [33] \\
& Hemangioblastoma [27] \\
& Cavernous hemangioma [63] \\
& Pituitary adenoma [63] \\
& Malignant peripheral nerve sheet tumor [63] \\
& Nasal glioma [25] \\
& Atypical teratoid-rhabdoid [20] \\
Intradural chordoma [15] & Chondrosarcoma [63] \\
Primary & Paraganglioma [30] \\
& Rhabdomyosarcoma [63] \\
Hematologic malignancies & Primary malignant lymphoma [26] \\
& Multiple myeloma [32] \\
& NK/T lymphoma [63] \\
& Diffuse B-cell lymphoma* \\
& Plasmacytoma [63] \\
& Marginal zone lymphoma [63] \\
& Chronic eosinophilic leukemia [63] \\
& Lymphoplasmocytic lymphoma [63] \\
& Non-Hodgkin lymphoma [63] \\
Inflammatory & Adenoid cystic carcinoma [5] \\
& Malignant melanotic schwannoma [23, 61, 101] \\
& Squamous cell carcinoma [63] \\
& Adenocarcinoma [63] \\
& Sarcoidosis [19, 69] \\
& Amyloidoma [22, 24, 28] 61, 64] \\
& IgG4 disease [63] \\
Metastatic & Necrotizing granulomatous inflammation [63] \\
& \\
& \\
&
\end{tabular}

*Illustrative case report presented in this article

and capacities of each institution will also play a role in decision-making. However, whatever skull base approach is applied, it has to be studied in detail and performed with experience to achieve excellent results.

The endoscopic endonasal approach provides safe access to Meckel's cave [7], with the transpterygoidal route supported by the most clinical reporting. If needed, the possibility for further tumor removal is given. The discussed approaches

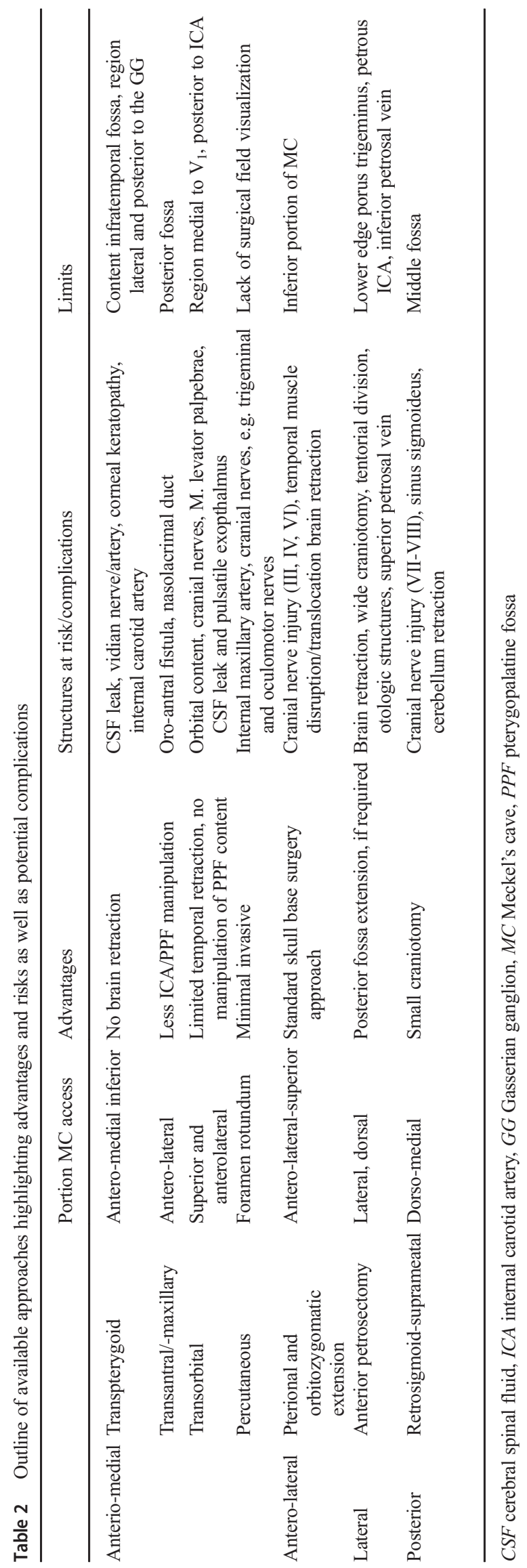


should, however, be seen as complementary and not competitive [73], since each one of them carries its own risks and advantages. Even though newly described endoscopic approaches appear promising, clinical experiences remain to be reported and an advanced anatomical knowledge of the neurovascular array within and surrounding the skull base is of utmost priority to assure safety during and after procedures. Hence, outcome reports from clinical series are further needed and case selection should be thoroughly discussed (Table 2).

\section{Limitations}

The amount of data available in the literature is by now immense. Our description is limited by the amount of data that is possible to include in a review article. We hope, however, to have provided a practical review of 360-degree approaches to Meckel's cave, encouraging critical thinking and evaluation of lesions.

\section{Conclusions}

This work, in an effort to shed light on the various routes to this region, provides an overview of the variance of approaches for reaching Meckel's cave. Anatomical landmarks and their variations, as well as the disease extension, are essential when planning a surgical approach to Meckel's cave. For lesions especially in the anterior, inferior and medial compartment of Meckel's cave, the extended endoscopic endonasal transpterygoidal approach is an excellent approach for targeting these lesions [69]. Numerous of these approaches are complementary to each other. Hence, open approaches are to be selected when necessary.

It is clear that skull base surgeons should learn and study the different approaches and include them in their surgical armamentarium, to provide the safest route according to the underlying pathology.

Acknowledgments We would like to thank Paula Frasch for her contribution in creating Fig. 1.

Funding Information Open Access funding provided by Projekt DEAL.

\section{Compliance with ethical standards}

Conflict of interest Dr. Prevedello is a consultant for Medtronic, Integra and Stryker; has received honoraria from Mizuho and has a royalty agreement with Mizuho, KLS-Martin and ACE Medical. Dr. Carrau is a consultant for Medtronic. The other authors report no conflict of interest concerning the materials or methods used in this study or the findings specified in this paper.

Ethical statement and informed consent For this type of systematic review, formal ethic committee consent is not required. Written informed patient consent for the illustrative case was acquired.
Open Access This article is licensed under a Creative Commons Attribution 4.0 International License, which permits use, sharing, adaptation, distribution and reproduction in any medium or format, as long as you give appropriate credit to the original author(s) and the source, provide a link to the Creative Commons licence, and indicate if changes were made. The images or other third party material in this article are included in the article's Creative Commons licence, unless indicated otherwise in a credit line to the material. If material is not included in the article's Creative Commons licence and your intended use is not permitted by statutory regulation or exceeds the permitted use, you will need to obtain permission directly from the copyright holder. To view a copy of this licence, visit http://creativecommons.org/licenses/by/4.0/.

\section{References}

1. Kawase T, Toya S, Shiobara R, Mine T (1985) Transpetrosal approach for aneurysms of the lower basilar artery. J Neurosurg 63: 857-861

2. Muto J, Kawase T, Yoshida K (2010) Meckel's cave tumors: relation to the meninges and minimally invasive approaches for surgery: anatomic and clinical studies. Neurosurgery 67:291-298; discussion ons298-299

3. Seoane E, Rhoton AL Jr (1999) Suprameatal extension of the retrosigmoid approach: microsurgical anatomy. Neurosurgery 44:553-560

4. Inoue T, Rhoton AL Jr, Theele D, Barry ME (1990) Surgical approaches to the cavernous sinus: a microsurgical study. Neurosurgery 26:903-932

5. Kassam AB, Prevedello DM, Carrau RL, Snyderman CH, Gardner P, Osawa S et al (2009) The front door to meckel's cave: an anteromedial corridor via expanded endoscopic endonasal approach- technical considerations and clinical series. Neurosurgery 64:71-82; discussion ons82-73

6. Arslan M, Deda H, Avci E, Elhan A, Tekdemir I, Tubbs RS, Silav G, Yilmaz E, Baskaya MK (2012) Anatomy of Meckel's cave and the trigeminal ganglion: anatomical landmarks for a safer approach to them. Turk Neurosurg 22:317-323

7. Fortes FS, Sennes LU, Carrau RL, Brito R, Ribas GC, Yasuda A, Rodrigues AJ Jr, Snyderman CH, Kassam AB (2008) Endoscopic anatomy of the pterygopalatine fossa and the transpterygoid approach: development of a surgical instruction model. Laryngoscope 118:44-49

8. Samii M, Tatagiba M, Carvalho GA (2000) Retrosigmoid intradural suprameatal approach to Meckel's cave and the middle fossa: surgical technique and outcome. J Neurosurg 92:235-241

9. Taha JM, Tew JM Jr, van Loveren HR (1995) Keller JT, el-Kalliny M: comparison of conventional and skull base surgical approaches for the excision of trigeminal neurinomas. J Neurosurg 82:719 725

10. Truong HQ, Sun X, Celtikci E, Borghei-Razavi H, Wang EW, Snyderman CH et al (2018) Endoscopic anterior transmaxillary "transalisphenoid" approach to Meckel's cave and the middle cranial fossa: an anatomical study and clinical application. J Neurosurg 130:227-237

11. Alfieri A, Jho HD, Schettino R, Tschabitscher M (2003) Endoscopic endonasal approach to the pterygopalatine fossa: anatomic study. Neurosurgery 52:374-378-378-380

12. Cavallo LM, Cappabianca P, Galzio R, Iaconetta G, de Divitiis E, Tschabitscher M (2005) Endoscopic transnasal approach to the cavernous sinus versus transcranial route: anatomic study. Neurosurgery 56:379-389; discussion 379-389 
13. Dolci RL, Upadhyay S, Ditzel Filho LF, Fiore ME, Buohliqah L, Lazarini PR et al (2016) Endoscopic endonasal study of the cavernous sinus and quadrangular space: Anatomic relationships. Head Neck 38(Suppl 1):E1680-E1687

14. Hofstetter CP, Singh A, Anand VK, Kacker A, Schwartz TH (2010) The endoscopic, endonasal, transmaxillary transpterygoid approach to the pterygopalatine fossa, infratemporal fossa, petrous apex, and the Meckel cave. J Neurosurg 113:967-974

15. Akay A, Gode S, Cagli MS (2017) Neuronavigation-guided endoscopic endonasal excision of schwannoma-like chordoma of the Meckel's cave: a case report. Turk Neurosurg

16. Allibone JB, Casey AT, Powell M, Cheeseman AD (2001) The midface degloving approach for intracranial tumours. Br J Neurosurg 15:109-115

17. Arai A, Sasayama T, Koyama J, Fujita A, Hosoda K, Kohmura E (2010) Epidermoid cyst in Meckel's cave with unusual computed tomography and magnetic resonance imaging findings. Case report. Neurol Med Chir (Tokyo) 50:701-704

18. Arishima H, Sindou M (2010) Benefits and pitfalls of percutaneous biopsy for cavernous sinus tumors through the foramen ovale: two case reports. Minim Invasive Neurosurg 53:194-197

19. Bangiyev L, Kornacki S, Mikolaenko I (2015) Rare isolated trigeminal nerve sarcoidosis mimicking schwannoma. Clin Imaging 39:133-135

20. Beschorner R, Mittelbronn M, Koerbel A, Ernemann U, Thal DR, Scheel-Walter HG, Meyermann R, Tatagiba M (2006) Atypical teratoid-rhabdoid tumor spreading along the trigeminal nerve. Pediatr Neurosurg 42:258-263

21. Bigder MG, Helmi A, Kaufmann AM: Trigeminal neuropathy associated with an enlarging arachnoid cyst in Meckel's cave: case report, management strategy and review of the literature. Acta Neurochir, 2017

22. Bookland MJ, Bagley CA, Schwarz J, Burger PC, Brem H (2007) Intracavernous trigeminal ganglion amyloidoma: case report. Neurosurgery 60:E574-discussion E574

23. Falavigna A, Borba LA, Ferraz FA, Almeida GC, Krindges Junior JV (2004) Primary melanoma of Meckel's cave: case report. Arq Neuropsiquiatr 62:353-356

24. Gultasli N, van den Hauwe L, Bruneau M, D'Haene N, Delpierre I, Baleriaux D (2012) Bilateral Meckel's cave amyloidoma: a case report. J Neuroradiol 39:119-122

25. Kasliwal MK, Anand VK, Lavi E, Schwartz TH (2010) Endoscopic management of a rare case of nasal glioma in Meckel's cave in an adult: case report. Minim Invasive Neurosurg 53:191-193

26. Kinoshita M, Izumoto S, Oshino S, Nonaka M, Moriuchi S, Maruno $M$ et al (2003) Primary malignant lymphoma of the trigeminal region treated with rapid infusion of high-dose MTX and radiation: case report and review of the literature. Surg Neurol 60: 343-348; discussion 348

27. Kord Valeshabad A, Xiao L, Amin-Hanjani S, Alsadi A, ValyiNagy T, Kim J (2018) Sporadic Hemangioblastoma of the cavernous sinus and Meckel's cave. J Neurol Surg Rep 79:e98-e102

28. Menetti F, Bartolomei I, Ambrosini-Spaltro A, Salvi F, Agati R, Leonardi M (2009) Amyloidoma involving the orbit, Meckel's cave and Infratemporal Fossa: $3 \mathrm{~T}$ MRI findings. Neuroradiol J 22:41-47

29. Nadkarni T, Dindorkar K, Muzumdar D, Goel A (2000) Epidermoid tumor within Meckel's cave-case report. Neurol Med Chir (Tokyo) 40:74-76

30. Prajsnar A, Balak N, Walter GF, Stan AC, Deinsberger W, Tapul L et al (2011) Recurrent paraganglioma of Meckel's cave: case report and a review of anatomic origin of paragangliomas. Surg Neurol Int 2:45

31. Seckin H, Patel N, Avci E, Dempsey RJ, Baskaya MK (2009) Removal of cavernous malformation of the Meckel's cave by extradural pterional approach using Heros muscle dissection technique. Surg Neurol 72:733-736; discussion 736

32. Thiruvengadam SS, Prayson RA (2016) Multiple myeloma presenting with unilateral abducens and trigeminal nerve palsies. J Clin Neurosci 26:143-144

33. Tobias S, Kim CH, Sade B, Staugaitis SM, Lee JH (2006) Neuromuscular hamartoma of the trigeminal nerve in an adult. Acta Neurochir (Wien) 148:83-87; discussion 87

34. Worner BA, Noll M, Rahim T, Fink U, Oeckler R (2003) Recurrent arachnoid cyst of Meckel's cave mimicking a brain stem ischaemia Report of a rare case. Zentralbl Neurochir 64: 76-79

35. Yong XZ, Dillon J, Smith P, Salinas-La Rosa C, Jhamb A (2017) Novel CT-guided biopsy of isolated perineural spread of adenoid cystic carcinoma along the trigeminal nerve masquerading as chronic trigeminal neuropathy. J Med Imaging Radiat Oncol 61: $77-81$

36. Acerbi F, Broggi M, Gaini SM, Tschabitscher M (2010) Microsurgical endoscopic-assisted retrosigmoid intradural suprameatal approach: anatomical considerations. J Neurosurg Sci 54:55-63

37. Alvernia JE, Sindou MP, Dang ND, Maley JH, Mertens P (2010) Percutaneous approach to the foramen ovale: an anatomical study of the extracranial trajectory with the incorrect trajectories to be avoided. Acta Neurochir 152:1043-1053

38. Bai ZQ, Cai EY, Wang SQ, Li ZJ, Wang SB (2009) Nasal cavitymaxillary sinus-pterygopalatine fossa-Meckel's cave: a preliminary anatomic study of an endoscopy-based operative approach. Neurosci Bull 25:376-382

39. Barges-Coll J, Fernandez-Miranda JC, Prevedello DM, Gardner P, Morera V, Madhok R et al (2010) Avoiding injury to the abducens nerve during expanded endonasal endoscopic surgery: anatomic and clinical case studies. Neurosurgery 67:144-154; discussion 154

40. Chanda A, Nanda A (2002) Partial labyrinthectomy petrous apicectomy approach to the petroclival region: an anatomic and technical study. Neurosurgery 51:147-159; discussion 159-160

41. Chanda A, Nanda A (2006) Retrosigmoid intradural suprameatal approach: advantages and disadvantages from an anatomical perspective. Neurosurgery 59:1-6

42. Chang SW, Wu A, Gore P, Beres E, Porter RW, Preul MC et al (2009) Quantitative comparison of Kawase's approach versus the retrosigmoid approach: implications for tumors involving both middle and posterior fossae. Neurosurgery 64:44-51; discussion ons $51-42$

43. de Jesus O (1996) Petrous apex region. Surgical anatomy, lesions, and operative techniques. P R Health Sci J 15:107-112

44. Dolci RLL, Ditzel Filho LFS, Goulart CR, Upadhyay S, Buohliqah L, Lazarini PR, Prevedello DM, Carrau RL (2018) Anatomical nuances of the internal carotid artery in relation to the quadrangular space. J Neurosurg 128:174-181

45. Ebner FH, Koerbel A, Kirschniak A, Roser F, Kaminsky J, Tatagiba M (2007) Endoscope-assisted retrosigmoid intradural suprameatal approach to the middle fossa: anatomical and surgical considerations. Eur J Surg Oncol 33:109-113

46. Ebner FH, Koerbel A, Roser F, Hirt B, Tatagiba M (2009) Microsurgical and endoscopic anatomy of the retrosigmoid intradural suprameatal approach to lesions extending from the posterior fossa to the central skull base. Skull Base 19:319-323

47. Ferrari M, Schreiber A, Mattavelli D, Belotti F, Rampinelli V, Lancini D, Doglietto F, Fontanella MM, Tschabitscher M, Rodella LF, Nicolai P (2016) The inferolateral Transorbital endoscopic approach: a preclinical anatomic study. World Neurosurg 90:403-413 
48. Fukushima T (1978) Endoscopy of Meckel's cave, cisterna magna, and cerebellopontine angle technical note. J Neurosurg 48:302306

49. Jacquesson T, Berhouma M, Tringali S, Simon E, Jouanneau E (2015) Which routes for Petroclival tumors? A Comparison Between the Anterior Expanded Endoscopic Endonasal Approach and Lateral or Posterior Routes. World Neurosurg 83: 929-936

50. Jacquesson T, Simon E, Berhouma M, Jouanneau E (2015) Anatomic comparison of anterior petrosectomy versus the expanded endoscopic endonasal approach: interest in petroclival tumors surgery. Surg Radiol Anat 37:1199-1207

51. Koerbel A, Kirschniak A, Ebner FH, Tatagiba M, Gharabaghi A (2009) The retrosigmoid intradural suprameatal approach to posterior cavernous sinus: microsurgical anatomy. Eur J Surg Oncol $35: 368-372$

52. Marcati E, Andaluz N, Froelich SC, Zimmer LA, Leach JL, Fernandez-Miranda JC, et al. (2018) Paratrigeminal, Paraclival, Precavernous, or all of the above? A circumferential anatomical study of the C3-C4 transitional segment of the internal carotid artery. Oper Neurosurg (Hagerstown) 14(4):432-440

53. Oyama K, Tahara S, Hirohata T, Ishii Y, Prevedello DM, Carrau RL et al (2017) Surgical anatomy for the endoscopic Endonasal approach to the Ventrolateral Skull Base. Neurol Med Chir (Tokyo) 57:534-541

54. Priddy BH, Nunes CF, Beer-Furlan A, Carrau R, Dallan I, Prevedello DM (2017) A side door to Meckel's cave: anatomic feasibility study for the lateral Transorbital approach. Oper Neurosurg (Hagerstown) 13:614-621

55. Rigante L, Herlan S, Tatagiba MS, Stanojevic M, Hirt B, Ebner FH (2016) Petrosectomy and topographical anatomy in traditional Kawase and posterior Intradural petrous Apicectomy (PIPA) approach: an anatomical study. World Neurosurg 86:93-102

56. Roche PH, Troude L, Peyriere H, Noudel R (2014) The epidural approach to the Meckel's cave: a how I do it. Acta Neurochir 156: 217-220

57. Van Rompaey J, Suruliraj A, Carrau R, Panizza B, Solares CA (2014) Meckel's cave access: anatomic study comparing the endoscopic transantral and endonasal approaches. Eur Arch Otorhinolaryngol 271:787-794

58. Wang J, Bidari S, Inoue K, Yang H, Rhoton A Jr (2010) Extensions of the sphenoid sinus: a new classification. Neurosurgery 66:797-816

59. Youssef S, Kim EY, Aziz KM, Hemida S, Keller JT, van Loveren HR (2006) The subtemporal interdural approach to dumbbellshaped trigeminal schwannomas: cadaveric prosection. Neurosurgery 59:270-277; discussion ONS277-278

60. Zhang X, Tabani H, El-Sayed I, Russell M, Feng X, Benet A (2017) The endoscopic Endonasal Transmaxillary approach to Meckel's cave through the inferior orbital fissure. Oper Neurosurg (Hagerstown) 13:367-373

61. Beck DW, Menezes AH (1987) Lesions in Meckel's cave: variable presentation and pathology. J Neurosurg 67:684-689

62. Goel A (1995) Infratemporal fossa interdural approach for trigeminal neurinomas. Acta Neurochir 136:99-102

63. Hughes JD, Kapurch J, Van Gompel JJ, Meyer FB, Pollock BE, Atkinson J et al (2017) Diagnosis and outcome of biopsies of indeterminate lesions of the cavernous sinus and Meckel's cave: a retrospective case series in 85 patients. Neurosurgery

64. Isaacson B, Coker NJ, Vrabec JT, Yoshor D, Oghalai JS (2006) Invasive cerebrospinal fluid cysts and cephaloceles of the petrous apex. Otol Neurotol 27:1131-1141

65. Jeon C, Hong CK, Woo KI, Hong SD, Nam DH, Lee JI, et al. (2018) Endoscopic transorbital surgery for Meckel's cave and middle cranial fossa tumors: surgical technique and early results. J Neurosurg 1:1-10
66. Kawase T, Shiobara R, Toya S (1991) Anterior transpetrosaltranstentorial approach for sphenopetroclival meningiomas: surgical method and results in 10 patients. Neurosurgery 28:869-875; discussion 875-866

67. Mariniello G, de Divitiis O, Caranci F, Dones F, Maiuri F (2017) Parasellar Schwannomas: extradural vs extra-Intradural surgical approach. Oper Neurosurg (Hagerstown)

68. Nakamura M, Krauss JK (2010) Image-guided resection of small lesions in the cavernous sinus and Meckel's cave. Eur J Surg Oncol 36:208-213

69. Palejwala SK, Zhao F, Lanker KC, Sivakumar W, Takasumi Y, Griffiths CF, Barkhoudarian G, Kelly DF (2018) Imagingambiguous lesions of Meckel's cave-utility of endoscopic Endonasal Transpterygoid biopsy. World Neurosurg 118:e346-e355

70. Raza SM, Donaldson AM, Mehta A, Tsiouris AJ, Anand VK, Schwartz TH (2014) Surgical management of trigeminal schwannomas: defining the role for endoscopic endonasal approaches. Neurosurg Focus 37:E17

71. Wang X, Zhang X, Hu F, Yu Y, Gu Y, Xie T et al (2016) Imageguided endoscopic Endonasal Transmaxillary Transpterygoid approach to Meckel's cave. Turk Neurosurg 26:309-314

72. Cheung SW, Jackler RK, Pitts LH, Gutin PH (1995) Interconnecting the posterior and middle cranial fossae for tumors that traverse Meckel's cave. Am J Otol 16:200-208

73. Hardesty DA, Montaser AS, Carrau RL, Prevedello DM (2018) Limits of endoscopic endonasal transpterygoid approach to cavernous sinus and Meckel's cave. J Neurosurg Sci 62:332-338

74. Jouanneau E, Simon E, Jacquesson T, Sindou M, Tringali S, Messerer M, Berhouma M (2014) The endoscopic endonasal approach to the Meckel's cave tumors: surgical technique and indications. World Neurosurg 82:S155-S161

75. Roche PH, Lubrano VF, Noudel R (2011) How I do it: epidural anterior petrosectomy. Acta Neurochir 153:1161-1167

76. Simal Julian JA, Miranda Lloret P, Garcia Pinero A, Botella Asuncion C (2014) Full endoscopic endonasal suprapetrous approach to Meckel's cave. Acta Neurochir 156:1623-1626

77. Kasemsiri P, Solares CA, Carrau RL, Prosser JD, Prevedello DM, Otto BA, Old M, Kassam AB (2013) Endoscopic endonasal transpterygoid approaches: anatomical landmarks for planning the surgical corridor. Laryngoscope 123:811-815

78. Kassam AB, Vescan AD, Carrau RL, Prevedello DM, Gardner P, Mintz AH, Snyderman CH, Rhoton AL (2008) Expanded endonasal approach: vidian canal as a landmark to the petrous internal carotid artery. J Neurosurg 108:177-183

79. Kassam AB, Gardner P, Snyderman C, Mintz A, Carrau R (2005) Expanded endonasal approach: fully endoscopic, completely transnasal approach to the middle third of the clivus, petrous bone, middle cranial fossa, and infratemporal fossa. Neurosurg Focus 19:E6

80. Kaen A, Cardenas Ruiz-Valdepenas E, Di Somma A, Esteban F, Marquez Rivas J, Ambrosiani Fernandez J (2018) Refining the anatomic boundaries of the endoscopic endonasal transpterygoid approach: the "VELPPHA area" concept. J Neurosurg 131(3): 911-919

81. Iwanaga J, Badaloni F, Laws T, Oskouian RJ, Tubbs RS (2018) Anatomic study of Extracranial needle trajectory using Hartel technique for percutaneous treatment of trigeminal neuralgia. World Neurosurg 110:e245-e248

82. Sindou M, Chavez JM, Saint Pierre G, Jouvet A (1997) Percutaneous biopsy of cavernous sinus tumors through the foramen ovale. Neurosurgery 40:106-110; discussion 110-101

83. Messerer M, Dubourg J, Saint-Pierre G, Jouanneau E, Sindou M (2012) Percutaneous biopsy of lesions in the cavernous sinus region through the foramen ovale: diagnostic accuracy and limits in 50 patients. J Neurosurg 116:390-398 
84. Al-Mefty O, Anand VK (1990) Zygomatic approach to skull-base lesions. J Neurosurg 73:668-673

85. Jian FZ, Santoro A, Innocenzi G, Wang XW, Liu SS, Cantore G (2001) Frontotemporal orbitozygomatic craniotomy to exposure the cavernous sinus and its surrounding regions. Microsurgical anatomy. J Neurosurg Sci 45:19-28

86. Dolenc VV (1994) Frontotemporal epidural approach to trigeminal neurinomas. Acta Neurochir 130:55-65

87. Day JD, Fukushima T, Giannotta SL (1994) Microanatomical study of the extradural middle fossa approach to the petroclival and posterior cavernous sinus region: description of the rhomboid construct. Neurosurgery 34:1009-1016

88. Kawase T, Shiobara R, Toya S (1994) Middle fossa transpetrosaltranstentorial approaches for petroclival meningiomas. Selective pyramid resection and radicality. Acta Neurochir 129:113-120

89. Drake CG (1965) Surgical treatment of ruptured aneurysms of the basilar artery. Experience with 14 cases. J Neurosurg 23:457-473

90. Spetzler RF, Hamilton MG, Daspit CP (1994) Petroclival lesions. Clin Neurosurg 41:62-82

91. Sanna M, Bacciu A, Pasanisi E, Taibah A, Piazza P (2007) Posterior petrous face meningiomas: an algorithm for surgical management. Otol Neurotol 28:942-950

92. Goel A, Nadkarni T (1999) Basal lateral subtemporal approach for trigeminal neurinomas: report of an experience with 18 cases. Acta Neurochir 141:711-719

93. Cushing H: Tumors of the nervus acusticus and the syndrome of the cerebellopontine angle: Philadelphia Saunders, 1917

94. O'Donoghue GM, O'Flynn P (1993) Endoscopic anatomy of the cerebellopontine angle. Am J Otol 14:122-125

95. Bambakidis NC, Kakarla UK, Kim LJ, Nakaji P, Porter RW, Daspit CP et al (2007) Evolution of surgical approaches in the treatment of petroclival meningiomas: a retrospective review. Neurosurgery 61:202-209; discussion 209-211

96. Siwanuwatn R, Deshmukh P, Figueiredo EG, Crawford NR, Spetzler RF, Preul MC (2006) Quantitative analysis of the working area and angle of attack for the retrosigmoid, combined petrosal, and transcochlear approaches to the petroclival region. $\mathrm{J}$ Neurosurg 104:137-142

97. Xu F, Karampelas I, Megerian CA, Selman WR, Bambakidis NC (2013) Petroclival meningiomas: an update on surgical approaches, decision making, and treatment results. Neurosurg Focus 35:E11

98. Cushing H, Eisenhardt L: Meningiomas: Their Classification, Regional Behavior, Life History, and Surgical End Results.: Springfield, Illinois, Charles C Thomas, 1938

99. Quencer RM, Stokes NA, Wolfe D, Page LK (1979) Melanotic nerve sheath tumor of the gasserian ganglion and trigeminal nerve. AJR Am J Roentgenol 133:142-144

100. Kimura H, Oka K, Nakayama Y, Tomonaga M (1991) Xanthoma in Meckel's cave. A case report. Surg Neurol 35:317-320

101. Levy WJ, Ansbacher L, Byer J, Nutkiewicz A, Fratkin J (1983) Primary malignant nerve sheath tumor of the gasserian ganglion: a report of two cases. Neurosurgery 13:572-576

102. Alobaid A, Schaeffer T, Virojanapa J, Dehdashti AR (2015) Rare cause of trigeminal neuralgia: Meckel's cave meningocele. Acta Neurochir 157:1183-1186

Publisher's note Springer Nature remains neutral with regard to jurisdictional claims in published maps and institutional affiliations. 